\title{
Uranium and its decay products in radioactive anomalies of oxidized brown coals (western part of Kansko-Achinsk brown coal basin)
}

\author{
M.S. Melgunov ${ }^{1}$, V.M. Gavshin ${ }^{1}$, E.V. Lazareva ${ }^{1}$ and E.A. Melgunova ${ }^{2}$ \\ ${ }^{1}$ V.S. Sobolev Institute of Geology and Mineralogy SB RAS, 630090 Novosibirsk, Russia \\ ${ }^{2}$ Boreskov Institute of Catalysis SB RAS, 630090 Novosibirsk, Russia
}

\begin{abstract}
Vertical distribution of uranium and its decay products $\left({ }^{226} \mathrm{Ra}\right.$ and $\left.{ }^{210} \mathrm{~Pb}\right)$ in the uppermost layers of the oxidised brown coals was studied for some deposits and natural outcrops of the Western part of the Kansko-Achinsk brown-coal basin. Abnormal accumulation of the mentioned radioactive elements is observed in all studied sites. Several types of radioactive anomalies are differed by the ratio of activities of ${ }^{238} \mathrm{U}$ and ${ }^{226} \mathrm{Ra}$ : 1) Equilibrium; 2) Radium; 3) Uranium. The depletion of ${ }^{210} \mathrm{~Pb}$ in the radioactive horizons of some sites indicates an active emanation of ${ }^{222} \mathrm{Rn}$ in the underlying coal layers. Uranium besides the form sorbed on coal is presented in poral solutions. It says about its potential mobility and is confirmed experimentally. Radium is actively absorbed by the plants growing on radioactive coals.
\end{abstract}

\section{INTRODUCTION}

Jurassic brown coals of the Kansko-Achinsk coal basin (Jurassic depositions of the southern edge of the Western-Siberian plate and the Siberian platform) are the actual source of combustible for thermal power stations and for house use by local population of the Western Siberia. This coal basin is unique due to its immense dimensions and giant reserves of brown coal suitable for opencast mining. Its reserves down to $1800 \mathrm{~m}$ depth were estimated as 1220 billion tons [1-3]. The Lower-Middle Jurassic coal-bearing formations in the western part of the basin formed a great syncline with gently sloping northern and southern limbs (Figure 1). The thickness of the coal layers reaches $60-80 \mathrm{~m}$. From West to East nine great coal deposits are distinguished: Tisul', Uryup, Barandat, Beryezovo, Kibiten', Altat, Nasarovo (southern limb of syncline), Itat, Bogotol (northern limb of syncline). The coal layers lay almost horizontally. Everywhere they are recoated by quaternary sediments. Coal deposits here are very convenient for an opencast mining. The typical unaltered coals are characterized by low trace elements content and has, correspondingly, a low radioactivity. According to literary data average contents of uranium in unaltered coals for various deposits of the western part of the Kansko-Achinsk basin vary from 1 up to $11 \mathrm{ppm}(12-140 \mathrm{~Bq} / \mathrm{kg})$. Ash content of such coals is 6-16\% [3-6]. Usually the upper part of the coal layers directly under quaternary sediments is oxidized. The uppermost horizons of coal $(0.5-$ $1.5 \mathrm{~m})$ are most oxidated. They often become friable and have sooty structure. Ash content increases here up to $25-35 \%$. Oxidized and especially "sooty" coals are often strongly enriched by uranium and its decay products $[3-5,7,10]$. Uranium content in "sooty" coals can reach $2100 \mathrm{ppm}(26000 \mathrm{~Bq} / \mathrm{kg})$. The radioactive anomalies connected with oxidized ("sooty") coals localized in some brown coal deposits of the western part of the Kansko-Achinsk coal basin are studied in this work.

\section{SAMPLING AND ANALYSES}

Distribution of uranium and its daughter products $\left({ }^{226} \mathrm{Ra}\right.$ and $\left.{ }^{210} \mathrm{~Pb}\right)$ was studied in the uppermost horizons of the oxidized brown coals which are lying down straight under recoating quarternary sediments. Sampling of the oxidized brown coals was carried out in the South-West part of the 


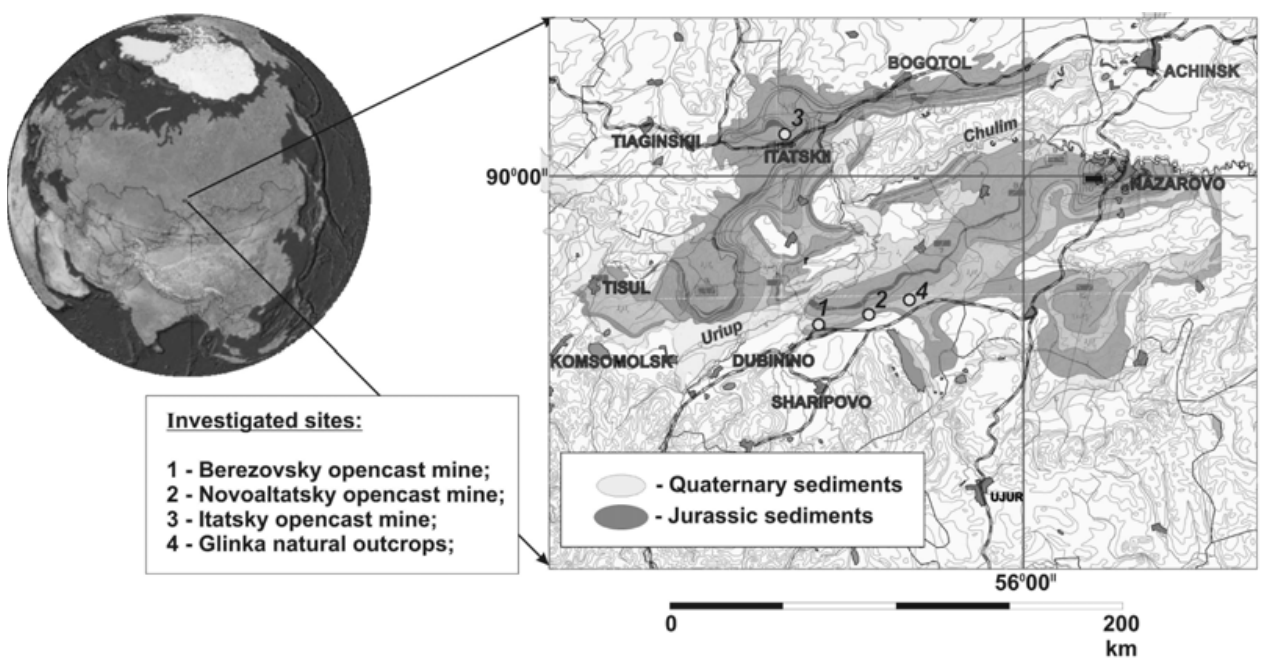

Figure 1. Map of the coal-bearing Jurassic formation in the West Siberia (the western part of the Kansko-Achinsk brown coal basin) and location of the sampling sites of the oxidized brown coals.

Kansko-Achinsk basin in active coal opencast mines (Berezovsky, Novoaltatsky and Itatsky), and in natural outcrops at Glinka village (Figure 1). Presence and the scope of radioactive anomalies were preliminarily investigated by means of the field radiometry followed by selection of representative samples for the laboratory gamma spectrometry analysis. In the absence of signs of radioactive anomalies the sampling was carried out in arbitrary points. Representative samples of coal were taken down to the depth of $0.5-2.5 \mathrm{~m}$ from the contact with overlying rocks with the steps $5,10 \mathrm{or} 20 \mathrm{~cm}$.

Definition of ${ }^{238} \mathrm{U},{ }^{226} \mathrm{Ra}$ and ${ }^{210} \mathrm{~Pb}$ contents in studied samples was carried out in laboratory using a high-resolution semiconductor gamma-spectrometry technique. Low-energy gamma lines were used as analytical signal: $46.5 \mathrm{keV}$ - for ${ }^{210} \mathrm{~Pb}, 63.3$ and $92 \mathrm{keV}-{ }^{238} \mathrm{U}$ (by ${ }^{234} \mathrm{Th}$ ) and $186.1 \mathrm{keV}-{ }^{226} \mathrm{Ra}$. At definition of radium the ${ }^{235} \mathrm{U}$ line $(185.7 \mathrm{keV})$ contribution was considered. The procedure was adapted for measuring $10 \mathrm{~cm}^{3}$ samples in the HPGe well-type detector $[8,9]$. Limits of detection of specified radioisotopes for $10 \mathrm{~cm}^{3}$ sample were not worse than $3 \mathrm{~Bq} \backslash \mathrm{kg}$ at the counting time equal to 24 hours.

\section{RESULTS AND DISCUSSION}

\subsection{Background radioactivity}

As it was mention earlier, average contents of uranium in unaltered brown coals of the Kansko-Achinsk basin vary in the range of $12-140 \mathrm{~Bq} / \mathrm{kg}$. In this study we take the value of $100 \mathrm{~Bq} \backslash \mathrm{kg}$ as the upper limit of the background for brown coals. For the background in a specific point we shall accept such level, below which the value of radioactivity is stabilized downward into the coal beds. Excess over the background is qualified as anomalies of a radioactivity.

\subsection{Radioactivity anomalies in the oxidized brown coals}

First of all, it is necessary to notice, that in all studied points including that, data on which have not been involved into the present work, radioactive NORM anomalies of various intensities and types are observed in the uppermost horizons of oxidized coals and especially in "sooty" coals. In this section the results characterizing the most typical distributions of ${ }^{238} \mathrm{U},{ }^{226} \mathrm{Ra}$ and ${ }^{210} \mathrm{~Pb}$ in these coal layers are presented. Diagrams characterizing the distributions of ${ }^{238} \mathrm{U},{ }^{226} \mathrm{Ra}$ and ${ }^{210} \mathrm{~Pb}$ are shown on Figure 2 


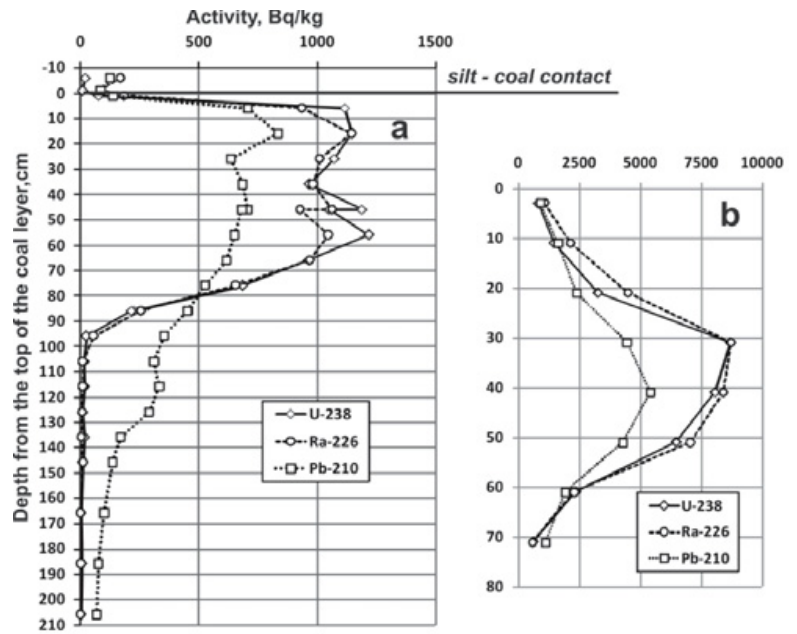

Figure 2. The "Equilibrium"-type radioactive anomalies in the oxidized brown coals. Selected sites (a and b) of the Glinka natural outcrop.

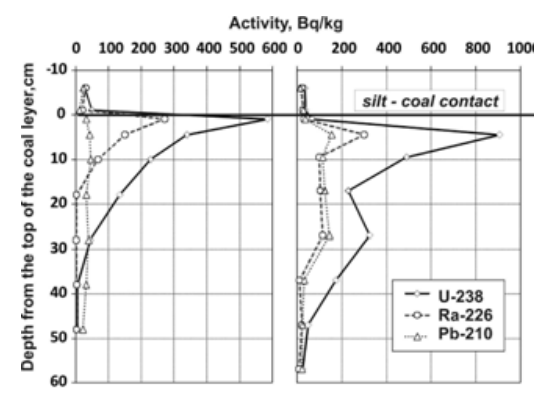

a

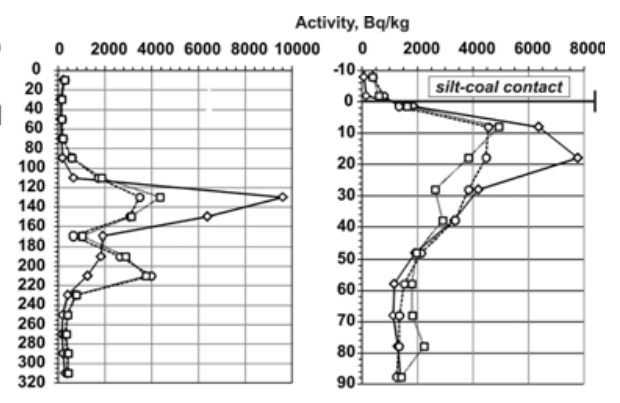

$\mathrm{b}$

Figure 3. The "Uranium"-type radioactive anomalies in the oxidized brown coals. Selected sites of the NovoAltatsky (a) and Itatsky (b) opencast mines.

(natural outcrops near the Glinka village), Figure 3 (Novo-Altatsky and Itatsky opencast mines) and Figure 4 (Berezovsky opencast mime). The analysis of data of Figures 2-4 shows that three types of radioactive anomalies can be distinguished by the ratio of activities of ${ }^{238} \mathrm{U}$ and ${ }^{226} \mathrm{Ra}$ : 1) Equilibrium; 2) Uranium; 3) Radium.

\subsubsection{The "Equilibrium"-type anomaly}

The "Equilibrium"-type anomaly is observed in the natural outcrops near the Glinka village (Figure 2). Such anomalies are characterized by presence of the quasi radioactive equilibrium between ${ }^{238} \mathrm{U}$ and ${ }^{226} \mathrm{Ra}$. This is the evidence of the absence of any modern significant geochemical processes which can lead to separation of $\mathrm{U}$ and its decay products.

\subsubsection{The "Uranium"-type anomaly}

In the "Uranium"-type anomalies ${ }^{238} \mathrm{U}$ prevails over its daughter products. It is the case of quite recent uranium migration and its enrichment relative to Ra, likewise in the Novo-Altatsky (Figure 3a) and 


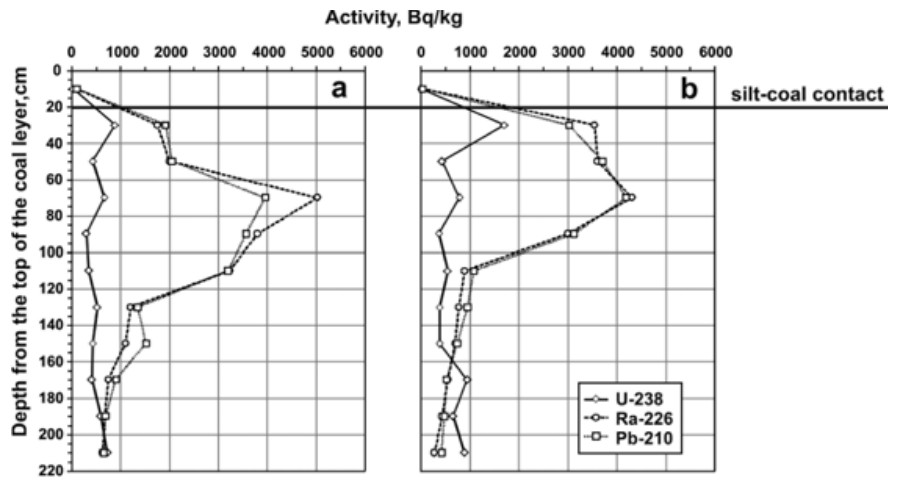

Figure 4. The "Radium"-type radioactive anomalies in the oxidized brown coals. Selected sites (a and b) of Berezovsky opencast mine.

Itatsky (Figure 3b) opencast mines. Sign of "Uranium"-type anomaly is presented in the lowest coal horizons in the Berezovsky opencast mine (Figure 4).

\subsubsection{The "Radium"-type anomaly}

For the "Radium"-type anomalies a considerable excess of Ra is observed. The strongest disequilibrium in the uranium family with significant deficiency of ${ }^{238} \mathrm{U}$ was found in the Berezovsky opencast mine (Figure 4). Signs of the "Radium"-type anomaly are visible in Itatsky opencast mine site (Figure 3b). Here underneath the uranium excess peak the second, radium one, can be seen. It is safe to say here about presence of some geochemical processes leading to removal of $\mathrm{U}$ already after accumulation of its decay products.

Disequilibrium caused by natural Rn emanation in coals is observed in the Glinka village sites (Figure 2) and in the upper horizons of the Novo-Altatsky opencast mine sites (Figure 3a). It was fixed by depletion of ${ }^{210} \mathrm{~Pb}$ resulted from migration of its predecessor - heavy ${ }^{222} \mathrm{Rn}$ outside the U-Ra anomaly.

\subsection{To the question of the NORM mobility in "sooty" coals}

\subsubsection{Uranium in poral solutions}

Poral solutions of "sooty" coal are characterized by near to neutral pH (see Figure 5). It weakly, but steadily decreases downwards of the profile from 7.6 up to 7 with small, but appreciable decrease up to 5.8 in the horizon with presence of gypsum formations. The redox potential varies on the profile from 390 up to 520, and it is possible to say, that it increases with depth.In poral solutions uranium is distributed extremely non-uniformly on the profile. In the most weathered (the upper) horizon of coal uranium concentration reaches up to $714 \mathrm{mkg} / \mathrm{l}$, but already in under laying horizon it strongly decreases up to $29 \mathrm{mkg} / \mathrm{l}$. High uranium concentration in the upper coal horizon causes high content of $\mathrm{U}$ in the poral solution of the soil horizon where its concentration reaches $198 \mathrm{mkg} / \mathrm{l}$. It is necessary to draw attention on discrepancy of maximal concentrations of uranium in poral solutions and in solid coal. Enrichment of weathered (sooty) coals by various microelements, including uranium, is connected with formation of abundance of humic acids in the weathered processes, capable to bond large concentration of microelements.

\subsubsection{NORM migration to plants}

To assess the possible migration of NORM to plants growing on the contaminated territory samples of herb were taken in two points at the Glinka natural outcrop. 1 - in immediate proximity from 


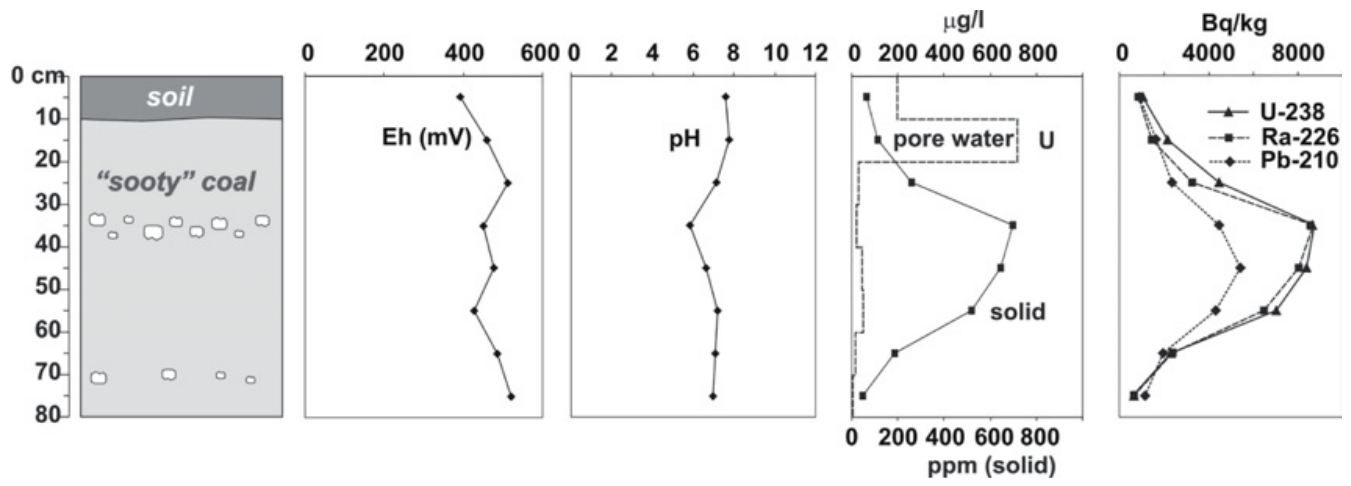

Figure 5. Profile of the "sooty" coal at the Glinka natural outcrop (Figure 2. Eh, pH of poral solutions and distribution of NORM in the profile.

Table 1. Radionuclides specific activity in herb, Bq/kg.

\begin{tabular}{|l|c|c|c|c|c|c|c|c|c|c|c|c|}
\hline Point & Dry w., & Ash w., & \multicolumn{5}{|c|}{ Ash } & \multicolumn{4}{|c|}{ Dry mass } \\
\hline num. & gr & gr & ${ }^{238} \mathbf{U}$ & ${ }^{210} \mathbf{P b}$ & ${ }^{226} \mathbf{R a}$ & ${ }^{137} \mathbf{C s}$ & ${ }^{40} \mathbf{K}$ & ${ }^{238} \mathbf{U}$ & ${ }^{210} \mathbf{P b}$ & ${ }^{226} \mathbf{R a}$ & ${ }^{137} \mathbf{C s}$ & ${ }^{40} \mathbf{K}$ \\
\hline $\mathbf{1}$ & 182.3 & 10.3 & 186 & 834 & 6145 & 24 & 5702 & 10.5 & 47.1 & 347.2 & & 322 \\
\hline $\mathbf{2}$ & 196.4 & 17.5 & 11 & 432 & 193 & 12 & 3645 & 0.98 & 38.5 & 17.2 & & 325 \\
\hline $\mathbf{3}$ & 162.4 & 10.9 & 0.3 & 592 & 1.1 & 20 & 5480 & 0.02 & 39.7 & 0.07 & & 368 \\
\hline
\end{tabular}

site with maximal NORM activity (Figure 5, up to $9000 \mathrm{~Bq} / \mathrm{kg}$ in the upper $40 \mathrm{~cm}, \mathrm{~S}=0.25 \mathrm{M}^{2}$ ). 2 - in $30 \mathrm{~m}$ from the point 1 . NORM concentrations in soil here are increased in comparison with background values (100-300 Bq/kg in the upper $30 \mathrm{~cm}, \mathrm{~S}=0.5 \mathrm{M}^{2}$ ). A background sample of herb was taken outside the Glinka natural outcrop (point 3). NORM concentrations in soil here doesn't exceed $50 \mathrm{~Bq} / \mathrm{kg}\left(\mathrm{S}=0.25 \mathrm{M}^{2}\right)$. In the points 1 and 2 the thickness of soil horizon does not exceed $5 \mathrm{~cm}$. The root system of plants here practically completely located in an underlying coal layer. The results of definition of specific activities of radionuclides, ingressed in ashes and dry weight (the counted values) of the studied samples, are presented in Table 1.

The analysis of the data presented in the Table 1, shows on primary accumulation of radium by the plants growing on contaminated territory. It is necessary to note that radium is known as a barrierless element and can easily penetrate into plants [11]. The increased contents of ${ }^{210} \mathrm{~Pb}$ are connected primarily with atmospheric deposits. It is also confirmed by presence of ${ }^{137} \mathrm{Cs}$ in ash in the same proportions. The increased, but not as high as for radium, concentrations of uranium can be connected with processes of accumulation by plants and with dust particles deposit.

\subsubsection{NORM mobility in natural conditions}

For studying the mobility of the NORM in natural conditions an experiment on their sorption with use of the synthetic sorbent $\mathrm{NH}_{2}$-SBA-15 developed in Boreskov Institute of Catalysis (Novosibirsk, Russia) was carried out. $\mathrm{NH}_{2}$-SBA-15 material was prepared by anchoring of $\mathrm{NH}_{2}$-groups on a silicate support SBA-15 [12]. Mesophase SBA-15 was synthesized by interaction of soluble forms of $\mathrm{SiO}_{2}$ with the surfactant Pluronic P123 $\left((\mathrm{EO})_{20}(\mathrm{PO})_{70}(\mathrm{EO})_{20}\right)$ under $\mathrm{pH}$ 3. The synthetic mixture was magnetically stirred and heated at $90^{\circ} \mathrm{C}$ to provide hydrothermal treatment. The formed white precipitate was filtered, washed, dried and calcined at $550^{\circ} \mathrm{C}$ [13]. This material had a specific BET surface area $350 \mathrm{~m}^{2} / \mathrm{g}$ and pore volume $0,88 \mathrm{~cm}^{3} / \mathrm{g}$, the nitrogen content in the sample was $2 \mathrm{wt} \%$. Preliminary laboratory experiments have shown high sorption selectivity of the $\mathrm{NH}_{2}-\mathrm{SBA}-15$ material. 
Level of extraction of the nitrate form of uranium by this material has reached the value of more than $95 \%$. At the same time it has appeared inert properties in relation to ${ }^{226} \mathrm{Ra}$ and ${ }^{210} \mathrm{~Pb}(<2 \%)$. During the experiment the $\mathrm{NH}_{2}$-SBA-15 material was placed in a layer of highly radioactive coal (site with maximal NORM activity, Figure 5). The experimental material was remaining in natural conditions in the course of a year. Then it was removed as well as a layer of surrounding coal and measured in layers to determine the NORM concentrations. The received results show, that the sorbent layer $(2 \mathrm{~mm})$, being in direct contact with radioactive coal, is considerably enriched in ${ }^{238} \mathrm{U}$ (up to $2100 \mathrm{~Bq} / \mathrm{kg}$ ). In inner layers of the sorbent uranium is found only in trace concentrations. The contact layer of coal $(5 \mathrm{~mm})$ is slightly depleted by uranium in comparison with its average concentration in surrounding coal (3500 and $3810 \mathrm{~Bq} / \mathrm{kg}$ correspondingly). Concentrations of ${ }^{226} \mathrm{Ra}$ and ${ }^{210} \mathrm{~Pb}$ in the sorbent were not changed, remaining at a level less than $3 \mathrm{~Bq} / \mathrm{kg}$ even in the layer near the contact. Specific activities of these radionuclides here completely correspond to their average values for surrounding coal (4000 and $2600 \mathrm{~Bq} / \mathrm{kg}$ for ${ }^{226} \mathrm{Ra}$ and ${ }^{210} \mathrm{~Pb}$ correspondingly). This experiment, on the one hand, confirmed the selectivity of sorption properties of the $\mathrm{NH}_{2}$-SBA-15 material relative to uranium. On the other hand, it indicated the possible mechanism of mobility of the NORM in coals. Due to processes of diffusion the uranium presented in poral solutions passes from surrounding radioactive coals into surface layers of the sorbent and sorbs there with gradual alignment of its concentrations in the near contact layers. It is to be notice that this process proceeds in a rather limited volume.

\section{Acknowledgments}

This study was carried with the partial support of Integration Project no. 114 of the Siberian Branch of the Russian Academy of Sciences.

\section{References}

[1] Burtsev M.P., Kansk-Achinsk coal basin. Geology and coal-bearing potential (Sov. Sci. Acad. Press, Moscow, 1961) p. 138 (In Russian).

[2] Grigor'ev K.N., Kansk-Achinsk coal basin (Nedra Moscow 1968) p. 184 (In Russian).

[3] Gavrilov K.V. and Ozersky A.Yu., Kansk-Achinsk coal basin. (Nedra, Moscow, 1996) p. 271 (In Russian).

[4] Arbuzov S.I., Ershov V.V., Rikhvanov L.P et al., Rare-metal potential of Minusinsk basin coals (Publ SB RAS Branch Geo, Novosibirsk, 2003) p. 347 (In Russian).

[5] Arbuzov S.I. and Ershov V.V., Geochemistry or rare elements in coals of Siberia (D-Print, Tomsk, 2007) p. 468 (In Russian).

[6] Yudovich Ya.E. and Ketris M.P., Valuable trace elements in coal (UrO RAN, Ekaterinburg, 2006) p. 538 (In Russian).

[7] Gavshin V.M. and Miroshnichenko L.V., Geostandards Newsletter 14 (2000) 241-246.

[8] Melgunov M.S., Gavshin V.M. Sukhorukov F.V., et al., Chem. for Sustainable Development 11 (2003) 869-880 (In Rusian).

[9] Gavshin V.M., Melgunov M.S., Sukhorukov F.V., Bobrov V.A. et al., J. Env. Radioact. 83 (2005) 61-74.

[10] Melgunov M.S., Gavshin V.M., Lazareva E.V., "Uranium and its decay products in radioactive anomalies of the oxidized brown coals (the western part of the Kansko-Achinsk brown coal basin)", Uranium, Mining and Hydrogeology, B.J. Merkel and A. Hasche-Berger Eds. (Springer, 2008) pp. 873-880.

[11] Titaeva N.A., Nuclear Geochemistry (Moscow Univ. Pr., Moscow, 2000) p. 336 (in Russian).

[12] Maksimchuk N.V., Melgunov M.S., Chesalov Yu.A., Mrowiec-Białoń J., Jarzêbski A.B., Kholdeeva O.A., Journal of Catalysis 246 (2007) 241-248.

[13] Mel'gunov M.S., Mel'gunova E.A., Shmakov A.N., Zaikovskii V.I., Studies in Surface Science and Catalysis 146 (2003) 543-546. 